\title{
Tree growth-competition relationships in thinned Eucalyptus plantations vary with stand structure and site quality
}

David I. Forrester, Stephen R. Elms, Thomas G. Baker

\section{David I. Forrester}

Department of Forest and Ecosystem Science, The University of Melbourne, 500 Yarra Boulevard, Richmond, Victoria 3121, Australia; Cooperative Research Centre for Forestry, Private Bag 12, Hobart 7001, Australia; and Institute of Silviculture, Freiburg University, D-79085 Freiburg, Germany. Email: davidif@unimelb.edu.au

\section{Stephen Elms}

HVP Plantations, 50 Northways Road, Churchill, VIC 3842, Australia; and Cooperative Research Centre for Forestry, Private Bag 12, Hobart 7001, Australia

Thomas G. Baker

Department of Forest and Ecosystem Science, The University of Melbourne, 500 Yarra Boulevard, Richmond, Victoria 3121, Australia; and Cooperative Research Centre for Forestry, Private Bag 12, Hobart 7001, Australia

\section{Abstract}

Growth responses to thinning can vary with site quality and age, however the direction of the response varies. An understanding of the mechanisms behind thinning responses could help forest managers optimise production as well as inform modellers and ecologists about the functioning of tree stands. Thinning was used to create a range of stand densities in eleven Eucalyptus plantation stands on seven sites in south-eastern Australia. Basal area periodic annual increment (PAI; $\mathrm{cm}^{2}$ year-1 $^{-1}$ ) of individual dominant and codominant trees was then related to competition, such that PAI $=a+b \ln ($ Competition). Competition was defined as the sum of the basal area of neighbouring trees within a radius of $6.5 \mathrm{~m}$. The relative (\%) and absolute $\left(\mathrm{cm}^{2} \mathrm{year}^{-1}\right)$ responses to competition were quantified using $b$, which was correlated with site quality and stand structure of unthined stands. Stand structure was quantified using statistics or parameters that describe the diameter distribution for the given age, species and site, including skewness, the coefficient of variation and parameters of the Weibull probability distribution. Relative and absolute responses both increased with increasing site quality and in stands with more 
negatively skewed diameter distributions (higher proportion of larger trees) or lower coefficients of variation. Absolute thinning responses often increased with increasing size class, while relative thinning responses often decreased. Variables describing diameter distributions (size-class structure) were able to describe some of the variation in competition responses that site quality could not. This indicates why stands on similar site qualities but with different stand structures can have correspondingly different thinning responses. Stand structural variables may be more useful predictors of thinning responses in stands that experience large temporal changes in diameter distributions compared with site quality, which is a more static variable. Thus, knowledge about the development of diameter distributions might help to refine thinning regimes.

Keywords: Eucalyptus globulus; Eucalyptus grandis; Eucalyptus nitens; fertilizer; competition symmetry; Weibull distribution; diameter distribution

\section{Introduction}

Thinning can be used to increase growth rates of remaining trees, reduce forest water use and drought stress, and improve resistance to pests and diseases (Bréda et al. 1995; Kolb et al. 2007; Forrester et al. 2010; Forrester et al. 2012b). For a given species, relative and absolute thinning responses can vary with resource availability (e.g. site quality or fertilizer application), size class and thinning age (Medhurst et al. 2001; Mäkinen and Isomäki 2004b). Site or fertilizer effects can be related, at least in part, to how they influence the symmetry of competition between trees. Competition for below-ground resources is often considered to be relatively symmetric (Weiner 1985; 1986; Hara 1993). Assuming below-ground resource uptake is proportional to fine-root surface area, a tree that is twice as large as its neighbour will obtain twice as much of the resource. In contrast, competition for light is more asymmetric because taller plants can shade smaller plants more than vice versa so a tree that is half the size of its neighbour may absorb much less than half as much light (Weiner 1985; 1986; Hara 1993; Kikuzawa and Umeki 1996).

In the context of thinning, the larger retained trees often have a greater absolute response on higher quality sites, or where fertilizer is applied, compared with large trees on lower quality sites or where fertilizer is not applied (Stoneman et al. 1996; Ruha and Varmola 1997; Mäkinen and Isomäki 2004a), but their relative thinning response can be smaller (Harrington and Wierman 1990; Messina 1992; Brockley 2005). This relative response could be expected because on higher quality sites, water and nutrients are not as limiting to growth relative to light, and since dominant trees already obtain the most light, removing smaller competing trees has a relatively smaller effect. In contrast, on lower quality sites, soil resources are relatively more limiting than light and since smaller trees can compete with larger trees for these resources, their removal could have a relatively larger effect on growth of the larger trees. However, there are cases where relative responses increased with 
increasing site quality or with rate of fertiliser application (Stoneman et al. 1996; Mäkinen and Isomäki 2004a; La Sala 2006), due to greater increases in leaf area index and basal area growth per unit leaf area index in fertilised stands than in unfertilised stands (Stoneman et al. 1996), and cases where there were no obvious trends (Messina 1992; Blevins et al. 2005; Omule et al. 2011). Therefore there are clearly factors in addition to site quality that influence these responses.

Application of the same theory about the symmetry of competition also suggests that relative, but not absolute, thinning responses by dominant trees are smaller than intermediate trees, and that this difference increases as stands age and dominance classes become more pronounced. Relative responses declined with increasing size class in Pseudotsuga menziesii, Betula papyrifera and heavily thinned Pinus sylvestris stands (Moore et al. 1994; Pukkala et al. 1998; Mäkinen and Isomäki 2004b; Simard et al. 2004). Conversely, absolute responses to thinning of even-aged stands often increase with increasing size class, with the larger and faster growing trees responding the most to thinning (Ruha and Varmola 1997; Medhurst et al. 2001; Mäkinen and Isomäki 2004b). Similarly, absolute and relative thinning responses will likely be greater when thinning is done close to the peak current annual volume increment, and eventually decline as growth rates decrease as stands age and trees differentiate into more size classes (Ruha and Varmola 1997; Mäkinen and Isomäki 2004b; a).

Thus site quality, size class and age all appear to influence thinning responses. However, the lack of consistent trends, even for a given species, suggests that other stand characteristics might also be indicators of responses to thinning. If symmetry of competition influences these responses, then information about stand structure is likely to be useful. For example, when diameter distributions are positively skewed and there is a high proportion of smaller trees in the stand, larger trees are already relatively free of competition and therefore less responsive to thinning than in stands that are negatively skewed where many large trees are competing with each other. Parameters that describe diameter distributions have proven useful in growth models (Peng 2000; Álvarez González et al. 2002; Lasch et al. 2005; Nord-Larsen and Cao 2006; Wang et al. 2011). These models account for the skewness, kurtosis and variability of the diameter distributions, often by including parameters that describe the shape and scale of the Weibull distribution. These parameters can vary with fertility and age (Nord-Larsen and Cao 2006) and may be able to capture the information required to predict thinning responses.

The aim of this study was to determine whether absolute and relative responses to reductions in competition in Eucalyptus plantations are related to (1) stand structure quantified in terms of the 
shape of the diameter distribution of unthinned stands as described by skewness, kurtosis, coefficient of variation (CV) and parameters of the Weibull distribution of tree diameters, and (2) if so, whether size-class structure is more closely related to competition responses than are site quality and stand age? A third aim was (3) to determine which size classes have the greatest absolute and relative responses.

\section{Methods}

Field experiments comprising combinations of seven sites and three species (E. globulus, E. nitens, E. grandis) were established between 1991 and 2003 in Victoria, Australia (Table 1) to examine plantation growth and yield responses to thinning treatments.

\section{Site characteristics}

Across the sites: (i) the means of daily minimum and maximum temperatures vary between $2-5^{\circ} \mathrm{C}$ and $11-14^{\circ} \mathrm{C}$ respectively in July, and $10-14^{\circ} \mathrm{C}$ and $23-30^{\circ} \mathrm{C}$ respectively in January, (ii) mean annual pan evaporation varies from 1132 to $1500 \mathrm{~mm}$, and (iii) mean annual rainfall varies from 483 to $1178 \mathrm{~mm}$. The Mangalore and Shepparton experiments were irrigated at rates of about 300 and $730 \mathrm{~mm}_{\text {year }}{ }^{-1}$ respectively. The previous land use at the Carrajung and Rennick sites was E. regnans and Pinus radiata plantations, respectively, and at all other sites was pasture. Site quality was quantified as the mean annual volume increment (MAI; $\mathrm{m}^{3} \mathrm{ha}^{-1}$ year $^{-1}$ ) of unthinned stands at age 10 years $\left(\mathrm{MAI}_{10}\right.$; see Table 1$)$. The sites were ranked in potential productivity: Carrajung $>$ Shepparton $>$ Buffalo River $=$ Rennick $>$ Tostaree $=$ Mangalore $>$ Bradvale, varying from 7 to $37 \mathrm{~m}^{3} \mathrm{ha}^{-1}$ year $^{-1}$.

\section{Establishment and experimental treatments}

The experiments were planted at 1000 to 1300 trees $^{-1} \mathrm{a}^{-1}$ with container grown seedling stock. Establishment involved: (i) soil deep ripping and bedding (Rennick was not deep-ripped), (ii) weeding using pre-planting (all sites) and post-planting (Shepparton and Tostaree) application of knock-down and pre-emergent herbicides, and (iii) fertiliser application to each seedling within 12 months of planting (equivalent to $0-280 \mathrm{~kg} \mathrm{ha}^{-1} \mathrm{~N}, 18-110 \mathrm{~kg} \mathrm{ha}^{-1} \mathrm{P}, 0-67 \mathrm{~kg} \mathrm{ha}^{-1} \mathrm{~K}$ ).

All experiments contained an unthinned reference and one, two or three thinning treatments which retained approximately 300,400 or 500 trees $^{-1} \mathrm{a}^{-1}$ Table 2). All experiments were arranged in 
randomized block designs with three replicates. Retained trees were selected on form (i.e. singlestemmed, straight, vertical), size (larger diameters), and spacing (uniformity) criteria, immediately prior to thinning. Thinning was carried out at canopy closure (Buffalo River, Mangalore and Shepparton), up to six months post-canopy closure (Bradvale and Carrajung) or about one (Rennick) and four (Tostaree) years post-canopy closure. Any coppice that grew on the stumps of thinned trees was removed annually. The main treatment plots of $0.12-0.15$ ha contained internal tree measurement plots of 0.07-0.12 ha. More details about the experimental designs are presented in Stackpole et al. (2004), Forrester and Baker (2012) and Forrester et al. (2012a). Fertilizer application treatments were also included at Carrajung where either nil or $300 \mathrm{~kg} \mathrm{ha}^{-1} \mathrm{~N}$ was applied in a factorial design at the same time as thinning (age 3.2 years). Fertiliser application treatments were also applied at Tostaree but the effects were not significant and the treatments are combined in the present study.

\section{Growth measurements and statistical analyses}

Tree diameter over bark at $1.3 \mathrm{~m}$ height $(\mathrm{cm})$ was measured for 6673, 3423 and 1507 E. globulus, $E$. nitens and E. grandis trees, respectively, two to four times and the positions of all trees were mapped. Trees were grouped into three main size-classes based on diameter; largest-diameter 200 trees $\mathrm{ha}^{-1}\left(D_{200}\right)$, the next largest $200\left(D_{200-400}\right)$ and then the next largest $200\left(D_{400-600}\right)$.

The growth of individual trees was quantified as basal area periodic annual increment (PAI; $\mathrm{cm}^{2}$ year $^{-1}$ ). The effects of competition, as affected by thinning, on PAI were examined on an individual tree level. This enabled a wider range, and higher number, of competition intensities to be examined than would be possible at the stand level where there were at most four thinning treatments, including an unthinned reference. A greater number of competition intensities at the tree level results from differences in relative tree sizes and spacing, and because the buffers between treatments can be used to provide intermediate conditions. Individual tree PAI was described as a function of local competition:

Basal area PAI = Constant + Slope $\ln ($ Competition $)$,

where competition is a competition index. Many competition indices have been used to quantify individual tree growth (e.g. Biging and Dobbertin, 1992). These often consider the number and size of neighbours, where size might be quantified as tree diameter, basal area, volume, biomass, height 
or crown size. Several approaches are also used to determine which trees are competitors, e.g. a fixed radius from the focal tree, or whether neighbouring tree crowns are inside an inverted cone above the focal tree (Biging and Dobbertin, 1992; Pretzsch, 2009, p. 293). Potential asymmetry of competition is sometimes accounted for by considering whether the focal tree is larger or smaller than its competitors. In this study, competition was relatively symmetric, as indicated by linear relationships between individual tree basal areas and their PAIs (Hara 1993) (data not shown). Competition was quantified as the sum of the basal areas $\left(\mathrm{cm}^{2}\right)$ of neighbouring trees within a radius, $r$, of a focal tree. This very simple distance-dependent index was used because it can be calculated quickly and easily by foresters and its simplicity facilitates interpretation. The optimal radius was determined using least squares where the coefficient of determination $\left(\mathrm{R}^{2}\right)$ of the relationship between PAI and competition was regressed against $r$ using the method described by Vanclay (2006) and Forrester et al. (2011) in Simile v4.7 (Simulistics, www.simulistics.com). The competition was recalculated along a continuous range of $r$ until the maximum $\mathrm{R}^{2}$ was found. All trees within a two-tree buffer of the edge of the plots were considered competitors of focal trees but not as focal trees themselves. The optimal $r$ was often about $6.5 \mathrm{~m}$, so this radius was used for all species and sites. This is similar to the 5-m radius that was found to be optimal in another $E$. globulus plantation (Forrester et al. 2011). For the fitting of Equation 1 competition was lntransformed so that the relationship was linear, to satisfy assumptions of normally distributed residuals and to remove heteroscedasticity. To compare the responses of different size classes, size class was added as a dummy variable to Equation 1 (see Figure 1).

Absolute PAI competition responses were calculated for each experiment and increment period using the fitted Equation 1 (Table 3) and for a reduction in competition from 3000 to $800 \mathrm{~cm}^{2}$. The relative response was this value relative to the PAI at competition $=3000 \mathrm{~cm}^{2}$, expressed as a percentage. Similarly, the Slope of Equation 1 can be used as a measure of the competition responses. Therefore, the effects of size-class structure and site quality on competition responses were quantified by examining the relationships between the Slope and $\mathrm{MAI}_{10}$, or the parameters used to describe the size-class structure of diameter distributions at the start of the given basal area growth period.

Size-class structure was quantified as the skewness, kurtosis and coefficient of variation of the diameter distribution of unthinned treatments at each age, species and site. The shape $(\alpha)$ and scale $(\beta)$ parameters of the cumulative distribution function for the Weibull distribution were also used, such that 
where $y$ is the cumulative proportional frequency of diameters in each 2 -cm class $(0 \leq \mathrm{y} \leq 1)$ and $x$ is the midpoint of the 2 -cm diameter class expressed as a proportion $(0 \leq \mathrm{x} \leq 1)$ of the maximum size-class. All statistical analyses were performed in Genstat ${ }^{\mathrm{TM}}$ (VSN International Ltd, Hemel Hemestead, U.K.).

\section{Results}

Basal area PAI declined with increasing competition at all sites (Figure 1; Table 3), although at Tostaree this relationship was often not significant. PAI-competition relationships were influenced by size class for all sites and species, such that for a given level of competition, basal area increment increased with increasing size-class (Figure 1). Absolute responses to reducing competition from 3000 to $800 \mathrm{~cm}^{2}$ were similar for each size class or increased with increasing sizeclass from $D_{400-600}$ to $D_{200-400}$ to $D_{200}$ (Figure 1). Relative competition responses were more variable, usually declining with increasing size-class, except for E. nitens at Buffalo River and E. globulus at Shepparton where it increased with increasing size-class. This resulted from a very small thinning response by the smaller size-classes at these sites (Figure 1d,e).

The Slope of the relationship between basal area PAI and ln Competition (Equation 1) was used to model competition responses of $D_{200}$ (Figure 2). Absolute responses ranged from about 3 to $63 \mathrm{~cm}^{2}$ year $^{-1}$ and relative responses from 11 to $136 \%$ when comparing the basal area increments of trees growing with a competition of $3000 \mathrm{~cm}^{2}$ with those experiencing only $800 \mathrm{~cm}^{2}$. This analysis was only done for $D_{200}$ trees because these are usually the most economically important in thinned Eucalyptus plantations and because the lowest levels of competition did not often exist for smaller size classes, which had been thinned out of more intensively thinned plots.

Competition responses were correlated with site quality and size-class structure. The Slope of Equation 1 was negatively correlated with site quality ( $\mathrm{MAI}_{10}$ ) (Figure 3a; Table 4). Based on this relationship and the trends shown in Figure 2, the absolute and relative thinning responses generally increased with increasing site quality. The Slope was also negatively correlated with the Weibull parameters and positively correlated with the skewness and coefficient of variation of unthinned stands at the start of the given basal area growth period (Figure 3b-e; Table 4). Thus competition 
responses were higher in stands that were more negatively skewed (higher proportion of large trees) and less variable. The Slope was not correlated with kurtosis $(P>0.05)$.

Generally as site quality increased, unthinned E. nitens stands were more negatively skewed and less variable (Figure 4). The same variables were not correlated for E. globulus stands. Size-class structure statistics and parameters (skewness, coefficient of variation, kurtosis or the Weibull parameters) did not change with age (data not shown). However, since site quality and size-class structure were both correlated with competition responses but not necessarily with each other, it appears as though these variables describe different, but useful information for predicting thinning responses. Multiple linear regressions were used to examine whether pairs of variables could be combined to increase the goodness of fit of models used to estimate the Slope of Equation 1, and hence the thinning response. The highest goodness of fit was obtained with Weibull- $\beta$ and either $\mathrm{MAI}_{10}$, the coefficient of variation, or Weibull- $\alpha$ (Adj $\mathrm{R}^{2} \geq 0.57$; Table 4). Examples of diameter distributions with a range of $\mathrm{MAI}_{10}$, skewness and coefficients of variation are shown in Figure 5ac. These are representative of high, medium and low competition (or thinning) responses shown in Figure 2.

\section{Discussion}

Absolute and relative competition responses of $D_{200}$ were correlated with site quality and size-class structure. Even though size-class structure was related to site quality for E. nitens this was not the case for E. globulus, and for both species, site quality and size-class structure complemented each other to more accurately describe the stand conditions that influenced competition responses. Absolute and relative responses by $D_{200}$ both increased with increasing site quality, in more negatively skewed, and more uniform stands.

Competition between trees is influenced by tree size, spacing and resource availability, and this study indicates that information about stand structure in terms of diameter distributions, as well as site quality, may be a useful way to summarise that information in order to predict thinning responses in Eucalyptus plantations. The potential of structural information to predict tree growth responses, though not necessarily to thinning, has been demonstrated in growth models that include information about diameter distributions or size cohorts in order to assign trees to specific diameter classes (Kellomäki and Väisänen 1997; Lasch et al. 2005; Wang et al. 2011). Others studies have included information about stand structure by describing tree growth as a function of competition from trees that are larger than the focal tree (Wykoff 1990; Monserud and Sterba 1996; Corral 
Rivas et al. 2005; Yang et al. 2009), by combining such competition indices with the relative spacing of trees within the stand (Schröder and Gadow 1999; Schröder et al. 2002), and by determining which trees are most likely to be competing neighbours (Biging and Dobbertin 1992).

In the Carrajung E. nitens experiment, more detailed examination of the mechanisms behind the thinning responses showed a combination of physiological and crown structural responses, which sometimes interacted with pruning and fertiliser application treatments. In thinned stands the $D_{200}$ trees had larger leaf areas and crowns, larger branches, longer crowns and a higher proportion of foliage in the lower crowns (Forrester et al. 2012a). This enabled $D_{200}$ trees to absorb $24 \%$ more light and transpire $23 \%$ more water than $D_{200}$ trees in unthinned stands (Forrester et al. 2012b; in press). In terms of the physiological responses, the lower crowns were better lit in thinned stands, resulting in faster rates photosynthesis, and $13 \%$ and $21 \%$ increases in light- and water-use efficiencies, respectively, by $D_{200}$ trees in thinned stands compared with those in unthinned stands (Forrester et al. 2012b; in press). Within unthinned stands, the capture and use-efficiency of resources was shown to increase with tree size in this and other stands (Forrester et al. 2012; Campoe et al. in press). This study shows that thinning responses also depend on site quality and size-class structure, probably because they modify the physiological and crown structural responses described above, and these effects likely vary between size classes.

\section{Absolute responses by $D_{200}$}

Absolute competition responses by $D_{200}$ were greater in stands that were more negatively skewed and had lower coefficients of variation. These size-class structures were more typical of faster growing stands and this explains why absolute responses to thinning often increase with site quality or fertilizer treatments (Stoneman et al. 1996; Ruha and Varmola 1997; Mäkinen and Isomäki 2004a). However, there are also cases where absolute responses have not increased with increasing site quality or fertilizer application (Harrington and Wierman 1990). This could occur if size-class structure is strongly affecting competition for responses. For example if $D_{200}$ are located in a more positively skewed stand, then they are competing with more smaller than larger trees. Such trees may be less responsive to thinning than $D_{200}$ in a stand that is more negatively skewed and/or more uniform where $D_{200}$ are not as dominant relative to their neighbours. 


\section{Relative responses by $D_{200}$}

Relative competition responses by $D_{200}$ were also higher in stands with more negatively skewed diameter distributions or that were more uniform. Such size-class structures could develop when the larger trees in the stand are growing at a similar rate and are not able to out-compete each other to differentiate into size classes. In the present study the more negatively skewed or less variable stands occurred on higher quality sites. Here thinning had a greater relative effect on growth than in stands where (i) size classes were more positively skewed so that $D_{200}$ were relatively more dominant, and (ii) stands were less uniform with a greater coefficient of variation. Greater relative thinning responses by dominant or codominant trees with increasing site quality or rates of fertilizer application have also been shown in E. marginata, E. obliqua and Pinus sylvestris stands (Stoneman et al. 1996; Mäkinen and Isomäki 2004a; La Sala 2006).

The opposite has also been found. On lower quality sites or in unfertilized stands of species such as Thuja plicata and Pinus contorta, which are more shade-tolerant than eucalypts, relative responses of the dominant or codominant trees to thinning were greater than on higher quality sites (Harrington and Wierman 1990; Brockley 2005). This may occur when competition is more asymmetric. In the young Eucalyptus stands in the present study, competition was relatively symmetric. This was indicated by minimal temporal changes in coefficients of variation of tree diameters (Kikuzawa and Umeki 1996) and linear relationships between individual tree basal areas and their PAIs (Hara 1993). In stands where size-class distribution is more spread out and with a higher coefficient of variation, for example in older stands or when the species is more shade tolerant (Nord-Larsen and Cao 2006), competition for light will become more asymmetric. Relationships between individual tree basal area and PAI may then slope upwards as larger trees grow proportionately more for their size than the smaller trees that they shade (Hara 1993). Thus unlike in the present study, thinning responses will be lower on higher quality sites because small trees cannot compete with larger trees for light, and higher on lower quality sites where soil resources are more limiting, and smaller trees can compete with larger trees for soil resources.

\section{Thinning responses by different size-classes}

The relative responses usually increased with decreasing size-class $\left(D_{400-600}>D_{200-400}>D_{200}\right)$, which has also been observed in many other studies (Moore et al. 1994; Pukkala et al. 1998; Mäkinen and Isomäki 2004b; Simard et al. 2004). This trend is likely because thinning does not only give smaller trees more water and nutrients, which is the case for larger trees, but it also increases light availability, which to some extent is not the case for larger trees. For example at 
Carrajung, thinning increased absorbed photosynthetically active radiation by about $50 \%$ for trees with diameters of about $10 \mathrm{~cm}$ compared to $30 \%$ for $30-\mathrm{cm}$ trees during the first year after thinning (see Forrester et al. (in press)). Nevertheless, this is often of little consequence because the smaller trees represent a much lesser proportion of the stand's growth.

In comparison to the $D_{200}$, the absolute response of $D_{200-400}$ and $D_{400-600}$ was similar or smaller. This is not surprising because PAI was linearly related to tree basal area, so the larger the tree the faster it grew. Decreasing absolute thinning responses with decreasing size class have been found in many other studies (Ruha and Varmola 1997; Medhurst et al. 2001; Mäkinen and Isomäki 2004b). Smaller trees are likely to have smaller leaf areas and fine-root masses, reducing their ability to take up resources, and they may also use those resources less efficiently than larger trees (Campoe et al. in press). However, some studies have shown that the most dominant trees do not have the largest absolute responses (Pukkala et al. 1998). This is likely related to stand age, shade tolerance and whether the stand is even-aged.

Genetic variability may also influence diameter distributions, which is important to consider, although it was not examined in this study. For example, all of the stands used in this study originated from seedlings as opposed to clonal cuttings, and size-class structure can be influenced by the degree of inbreeding within seed-origin stands (Costa e Silva et al. 2010). Inbred individuals will fall behind out-crossed individuals at some stage during stand development, and the proportion of inbred individuals varies between species, stands and sites (Costa e Silva et al. 2010; Grosser et al. 2010).

\section{Management implications}

Competition between trees is influenced by site quality as well as stand structure, which incorporates information about tree size and spacing. Diameter distributions appear to capture some of this information and were as good as, or better than, site quality at predicting thinning responses. Furthermore, site quality does not necessarily vary for a given site, while variables used to describe size-class structure can vary. Thus the latter may be more useful in stands that experience large changes in diameter distributions as they develop. This study also indicates that stands on similar site qualities but with different size-class structures can have correspondingly different thinning responses. Thus, knowledge about how diameter distributions develop might help to refine thinning regimes. Eucalyptus plantations with negatively skewed diameter distributions, which are fast growing and less variable are likely to show the greatest absolute and relative thinning responses, 
and the larger size-classes will have the largest absolute thinning responses. More uniform (e.g. clonal) Eucalyptus plantations might therefore also respond particularly well to thinning.

\section{Acknowledgements}

The studies presented and analysed here were supported by the Victorian Department of Primary Industries, and the Victorian Department of Sustainability and Environment (DSE), Forest and Wood Products Australia, and the Cooperative Research Centre for Forestry. HVP Plantations, Peart family, Goulburn Valley Region Water Authority and DSE provided sites, silvicultural assistance and some data. Numerous individuals contributed variously to trial design, establishment, maintenance and measurement, including A. Ashton, R. Bickford, R. Borschmann, J. Collopy, J. Costenaro, M. Duncan, P. Kneale, M. Lutze, M. McCormick, B. McGinniskin, D. Oswin, S. Lavell, S. Shaw, D. Stackpole, H. Stewart, R. Stokes and G. Wall. Dr. C. Beadle, Dr. C. Harwood and three anonymous reviewers provided useful comments, improving the manuscript.

\section{References}

Álvarez González JG, Schröder J, Rodríguez Soalleiro R, Ruíz González AD (2002) Modelling the effect of thinnings on the diameter distribution of even-aged Maritime Pine stands. For. Ecol. Manag. 165: 57-65.

Biging GS, Dobbertin M (1992) A comparison of distance-dependent competition measures for height and basal area growth of individual conifer trees. Forest Sci. 38: 695-720.

Blevins DP, Prescott CE, Allen HL, Newsome TA (2005) The effects of nutrition and density on growth, foliage biomass, and growth efficiency of high-density fire-origin lodgepole pine in central British Columbia. Can. J. For. Res. 35: 2851-2859.

Bréda N, Granier A, Aussenac G (1995) Effects of thinning on soil and tree water relations, transpiration and growth in an oak forest (Quercus petraea (Matt.) Liebl.). Tree Physiol. 15: 295-306.

Brockley RP (2005) Effects of post-thinning density and repeated fertilization on the growth and development of young lodgepole pine. Can. J. For. Res. 35: 1952-1964.

Campoe, O.C., Stape, J.L., Nouvellon, Y., Laclau, J.P., Bauerle, W.L., Binkley, D., Maire, G.L., in press. Stem production, light absorption and light use efficiency between dominant and non-dominant trees of Eucalyptus grandis across a productivity gradient in Brazil. For. Ecol. Manage.

Corral Rivas JJ, Álvarez González JG, Aguirre 0, Hernández J (2005) The effect of competition on individual tree basal area growth in mature stands of Pinus cooperi Blanco in Durango (Mexico). European Journal of Forest Research 124: 133-142.

Costa e Silva J, Hardner C, Tilyard P, Pires AM, Potts BM (2010) Effects of inbreeding on population mean performance and observational variances in Eucalyptus globulus. Ann. For. Sci. 67: 605.

Forrester DI, Baker TG (2012) Growth responses to thinning and pruning in Eucalyptus globulus, Eucalyptus nitens, and Eucalyptus grandis plantations in southeastern Australia. Can. J. For. Res. 42: 75-87. 
Forrester DI, Collopy JJ, Beadle CL, Baker TG (2012a) Interactive effects of simultaneously applied thinning, pruning and fertiliser application treatments on growth, biomass production and crown architecture in a young Eucalyptus nitens plantation. For. Ecol. Manag. 267: 104-116.

Forrester DI, Collopy JJ, Beadle CL, Baker TG (in press) Effect of thinning, pruning and nitrogen fertiliser application on light interception and light-use efficiency in a young Eucalyptus nitens plantation. For. Ecol. Manag.

Forrester DI, Collopy JJ, Beadle CL, Warren CR, Baker TG (2012b) Effect of thinning, pruning and nitrogen fertiliser application on transpiration, photosynthesis and water-use efficiency in a young Eucalyptus nitens plantation. For. Ecol. Manag. 266: 286-300.

Forrester DI, Medhurst JL, Wood M, Beadle CL, Valencia JC (2010) Growth and physiological responses to silviculture for producing solid-wood products from Eucalyptus plantations: An Australian perspective. For. Ecol. Manag. 259: 1819-1835.

Forrester DI, Vanclay JK, Forrester RI (2011) The balance between facilitation and competition in mixtures of Eucalyptus and Acacia changes as stands develop. Oecologia 166: 265-272.

Grosser C, Potts BM, Vaillancourt RE (2010) Microsatellite based paternity analysis in a clonal Eucalyptus nitens seed orchard. Silvae Genetica 59: 57-62.

Hara T (1993) Mode of competition and size-structure dynamics in plant communities. Plant Species Biology 8: 75-84.

Harrington CA, Wierman CA (1990) Growth and foliar nutrient response to fertilization and precommercial thinning in a coastal western red cedar stand. Can. J. For. Res. 20: 764-773.

Isbell R (2002) The Australian Soil Classification, Revised Edition. CSIRO Publishing, Melbourne.

Kellomäki S, Väisänen H (1997) Modelling the dynamics of the forest ecosystem for climate change studies in the boreal conditions. Ecol. Model. 97: 121-140.

Kikuzawa K, Umeki K (1996) Effect of canopy structure on degree of asymmetry of competition in two forest stands in northern Japan. Ann. Bot. 77: 565-571.

Kolb TE, Agee JK, Fule PZ, McDowell NG, Pearson K, Sala A, Waring RH (2007) Perpetuating old ponderosa pine. For. Ecol. Manag. 249: 141-157.

La Sala AV (2006) Pre-commercial thinning and fertiliser enhance growth in young native Eucalyptus obliqua (L'Hérit.) stands in Tasmania. Austral. For. 69: 16-24.

Lasch P, Badeck F-W, Felicitas Suckow, Lindner M, Mohr P (2005) Model-based analysis of management alternatives at stand and regional level in Brandenburg (Germany). For. Ecol. Manag. 207: 59-74.

Mäkinen H, Isomäki A (2004a) Thinning intensity and growth of Scots pine stands in Finland. For. Ecol. Manag. 201: 311-325.

Mäkinen H, Isomäki A (2004b) Thinning intensity and long-term changes in increment and stem form of Norway spruce trees. For. Ecol. Manag. 201: 295-309.

Medhurst JL, Beadle CL, Neilsen WA (2001) Early-age and later-age thinning affects growth, dominance, and intraspecific competition in Eucalyptus nitens plantations. Can. J. For. Res. 31: 187-197.

Messina MG (1992) Response of Eucalyptus regnans F. Muell. to thinning and urea fertilization in New-Zealand. For. Ecol. Manag. 51: 269-283.

Monserud RA, Sterba H (1996) A basal area increment model for individual trees growing in even- and unevenaged forest stands in Austria. For. Ecol. Manag. 80: 57-80. 
Moore JA, Zhang L, Newberry JD (1994) Effects of intermediate silvicultural treatments on the distribution of within-stand growth. Can. J. For. Res. 24: 398-404.

Nord-Larsen T, Cao QV (2006) A diameter distribution model for even-aged beech in Denmark. For. Ecol. Manag. 231: 218-225.

Omule AY, Mitchell AK, Wagner WL (2011) Fertilization and thinning effects on a Douglas-fir ecosystem at Shawnigan Lake: 32-year growth response Natural Resources Canada, Canadian Forest Service, Pacific Forestry Centre, Victoria, BC. Information Report FI-X-005., pp 22.

Peng C, (2000) Growth and yield models for uneven-aged stands: past, present and future. For. Ecol. Manag. 132: 259-279.

Pukkala T, Miina J, Kellomäki S (1998) Response to different thinning intensities in young Pinus sylvestris. Scand. J. Forest. Res. 13: 141-150.

Ruha T, Varmola M (1997) Precommercial thinning in naturally regenerated Scots Pine stands in northern Finland. Silva Fennica 31: 401-415.

Schröder J, Gadow Kv (1999) Testing a new competition index for Maritime pine in northwestern Spain. Can. J. For. Res. 29: 280-283.

Schröder J, Soalleiro RR, Alonso GV (2002) An age-independent basal area increment model for maritime pine trees in northwestern Spain. For. Ecol. Manag. 157: 55-64.

Simard SW, Blenner-Hassett T, Cameron IR (2004) Pre-commercial thinning effects on growth, yield and mortality in even-aged paper birch stands in British Columbia. For. Ecol. Manag. 190: 163-178.

Stackpole DJ, Duncan MJ, Smith MJ, Baker TG (2004) Value-Added Silvicultural Regimes for High Quality Timber Production from Intensively Managed Hardwood and Softwood Plantations, PN97.602 FaWPRaDC (ed) Forest Science Centre, Department of Sustainability and Environment, Melbourne, pp 55.

Stoneman GL, Crombie DS, Whitford K, Hingston FJ, Giles R, Portlock CC, Galbraith JH, Dimmock GM (1996) Growth and water relations of Eucalyptus marginata (jarrah) stands in response to thinning and fertilization. Tree Physiol. 17: 267-274.

Vanclay JK (2006) Spatially-explicit competition indices and the analysis of mixed-species plantings with the Simile modelling environment. For. Ecol. Manag. 233: 295-302.

Wang W, Peng C, Zhang SY, Zhou X, Larocque GR, Kneeshaw DD, Lei X (2011) Development of TRIPLEXManagement model for simulating the response of forest growth to pre-commercial thinning. Ecol. Model. 222: 2249-2261.

Weiner J (1985) Size hierarchies in experimental populations of annual plants. Ecology 66: 743-752.

Weiner J (1986) How competition for light and nutrients affects size variability in Ipomea tricolor populations. Ecology 67: 1425-1427.

Wykoff WR (1990) A basal area increment model for individual conifers in the Northern Rocky Mountains. Forest Sci. 36: 1077-1104.

Yang Y, Huang S, Meng SX, Trincado G, VanderSchaaf CL (2009) A multilevel individual tree basal area increment model for aspen in boreal mixedwood stands. Can. J. For. Res. 39: 2203-2214. 


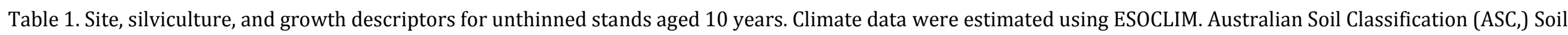
Order (Isbell 2002). Top height is the mean height of the largest-diameter 100 trees ha-1. $^{-1}$

\begin{tabular}{|c|c|c|c|c|c|c|c|c|}
\hline & & Bradvale & Buffalo River & Carrajung & Mangalore & Rennick & Shepparton & Tostaree \\
\hline Latitude, longitude & & $37^{\circ} 49^{\prime} \mathrm{S}, 143^{\circ} 25^{\prime} \mathrm{E}$ & $36^{\circ} 46^{\prime} \mathrm{S}, 146^{\circ} 40^{\prime} \mathrm{E}$ & $38^{\circ} 23^{\prime} \mathrm{S}, 146^{\circ} 41^{\prime} \mathrm{E}$ & $36^{\circ} 54^{\prime} \mathrm{S}, 145^{\circ} 11^{\prime} \mathrm{E}$ & $37^{\circ} 54^{\prime} \mathrm{S}, 150^{\circ} 59^{\prime} \mathrm{E}$ & $36^{\circ} 18^{\prime} \mathrm{S}, 145^{\circ} 23^{\prime} \mathrm{E}$ & $37^{\circ} 47^{\prime} \mathrm{S}, 148^{\circ} 11^{\prime} \mathrm{E}$ \\
\hline $\begin{array}{l}\text { Altitude (m, a.s.l.) } \\
\text { Soil description }\end{array}$ & & $\begin{array}{c}250 \\
\text { Cracking clay A } \\
\text { horizon, structureless } \\
\text { grey clay B horizon }\end{array}$ & $\begin{array}{l}290 \\
\begin{array}{c}\text { Clay loam A and B } \\
\text { horizons }\end{array}\end{array}$ & $\begin{array}{l}610 \\
\text { Silty loam to clay } \\
\text { loam A horizon, light } \\
\text { clay to medium clay B } \\
\text { horizon. }\end{array}$ & $\begin{array}{c}140 \\
\text { Loam A horizon, light } \\
\text { to medium clay B } \\
\text { horizon }\end{array}$ & $\begin{array}{c}60 \\
\text { Uniform coarse sand }\end{array}$ & $\begin{array}{c}100 \\
\text { Loam A horizon, } \\
\text { heavy clay B horizon }\end{array}$ & $\begin{array}{c}40 \\
\text { Loamy sand A } \\
\text { horizon, light to } \\
\text { medium clay B } \\
\text { horizon }\end{array}$ \\
\hline ASC Soil Order & & Vertosol & Dermosol & Dermosol & Kurosol & Podosol & Sodosol & Kurosol \\
\hline Mean daily & January & 25.6 & 29 & 22.3 & 28.5 & 23.4 & 29.8 & 25 \\
\hline $\max$ temp. $\left({ }^{\circ} \mathrm{C}\right)$ & July & 11.3 & 11.4 & 10.2 & 12.1 & 12.9 & 12.4 & 13.8 \\
\hline Mean daily & January & 10.6 & 11.7 & 11.1 & 13 & 11.1 & 14.2 & 12.2 \\
\hline $\min$. temp. $\left({ }^{\circ} \mathrm{C}\right)$ & July & 3.2 & 2.1 & 3.9 & 3 & 4.7 & 2.7 & 3 \\
\hline Mean annual pan evap. (mm) & & 1160 & 1245 & 1039 & 1359 & 1274 & 1500 & 1247 \\
\hline Mean annual rainfall (mm) & & 618 & 1178 & 1124 & 603 & 760 & 483 & 835 \\
\hline \multirow{2}{*}{\multicolumn{2}{|c|}{ Irrigation $\left(\mathrm{mm} \mathrm{year}^{-1}\right)$}} & Nil & Nil & Nil & $300^{*}$ & Nil & $730^{\dagger}$ & Nil \\
\hline & & E. globulus & E. globulus / E. nitens & E. nitens unfert / fert & $\begin{array}{l}\text { E. globulus / } \\
\text { E. grandis }\end{array}$ & E. globulus & $\begin{array}{l}\text { E. globulus / } \\
\text { E. grandis }\end{array}$ & E. globulus / E. nitens \\
\hline Planted & & Aug-97 & Oct-92 & Jun-03 & Oct-92 & Aug-97 & Sep-93 & Sep-91 \\
\hline Planting density (trees $\mathrm{ha}^{-1}$ ) & & $1000(4 \mathrm{~m} \times 2.5 \mathrm{~m})$ & $1111(3.0 \mathrm{~m} \times 3.0 \mathrm{~m})$ & $1000(4 \mathrm{~m} \times 2.5 \mathrm{~m})$ & $1235(2.7 \mathrm{~m} \times 3.0 \mathrm{~m})$ & $1000(4 \mathrm{~m} \times 2.5 \mathrm{~m})$ & $1333(3.0 \mathrm{~m} \times 2.5 \mathrm{~m})$ & $1143(3.5 \mathrm{~m} \times 2.5 \mathrm{~m})$ \\
\hline Density $\left(\right.$ trees $\mathrm{ha}^{-1}$ ) & & 917 & $799 / 743$ & $826 / 774$ & $696 / 848$ & 895 & $873 / 938$ & $836 / 702$ \\
\hline Top height (m) & & 13.9 & $27.1 / 26.7$ & $24.8 / 26.1$ & $20.6 / 19.0$ & 22.1 & $25.7 / 22.4$ & $23.8 / 22.2$ \\
\hline Basal area $\left(\mathrm{m}^{2} \mathrm{ha}^{-1}\right)$ & & 13.9 & $22.0 / 24.9$ & $33.7 / 35.5$ & $20.1 / 19.4$ & 28 & $27.4 / 18.7$ & $20.4 / 18.9$ \\
\hline Mean diameter $(\mathrm{cm})$ & & 13.5 & $18.4 / 20.4$ & $22.0 / 23.1$ & $19.3 / 16.6$ & 19.4 & $19.7 / 15.7$ & $17.0 / 17.9$ \\
\hline Mean annual increment $\left(\mathrm{m}^{3} \mathrm{~h}\right.$ & ${ }^{-1}$ year $\left.^{-1}\right)$ & 7.3 & $21.6 / 24.7$ & $33.1 / 36.4$ & $15.5 / 13.4$ & 21.9 & $25.3 / 15.1$ & $16.9 / 14.4$ \\
\hline
\end{tabular}

*Groundwater (electrical conductivity 0.6 dS m${ }^{-1}$ ) applied 3-5 times annually from October to May.

$\uparrow$ Secondary treated municipal effluent (electrical conductivity $1.4 \mathrm{dS} \mathrm{m}^{-1}$ ) applied 10-12 times annually from October to May. 


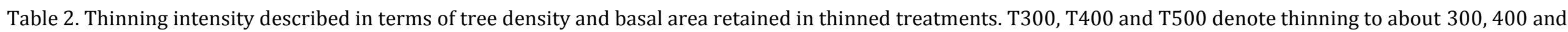
500 trees ha $^{-1}$, respectively.

\begin{tabular}{|c|c|c|c|c|c|c|c|c|c|c|c|c|c|}
\hline \multirow[t]{2}{*}{ Site } & \multirow[t]{2}{*}{ Species } & \multirow{2}{*}{$\begin{array}{c}\text { Age } \\
\text { thinned } \\
\text { (years) }\end{array}$} & \multirow{2}{*}{$\begin{array}{l}\text { Density prior } \\
\text { to thinning } \\
\left.\left(\text { trees }^{-1}\right)^{-1}\right)\end{array}$} & \multirow{2}{*}{$\begin{array}{l}\text { Basal area prior } \\
\text { to thinning }\left(\mathrm{m}^{2}\right. \\
\left.\mathrm{ha}^{-1}\right)\end{array}$} & \multicolumn{3}{|c|}{$\begin{array}{l}\text { Density after thinning } \\
\quad\left(\text { trees } \mathrm{ha}^{-1}\right)\end{array}$} & \multicolumn{3}{|c|}{$\begin{array}{l}\text { Basal area retained after } \\
\text { thinning }\left(\mathrm{m}^{2} \mathrm{ha}^{-1}\right)\end{array}$} & \multicolumn{3}{|c|}{ Basal area retained $(\%)$} \\
\hline & & & & & $\mathrm{T} 300$ & $\mathrm{~T} 400$ & T500 & $\mathrm{T} 300$ & $\mathrm{~T} 400$ & T500 & $\mathrm{T} 300$ & $\mathrm{~T} 400$ & T500 \\
\hline Bradvale & E. globulus & 5 & 965 & 6.2 & 300 & 410 & 540 & 2.4 & 3.9 & 4.3 & 39 & 64 & 69 \\
\hline \multirow{2}{*}{$\begin{array}{l}\text { Buffalo } \\
\text { River }\end{array}$} & E. globulus & 3.5 & 999 & 9.7 & 231 & & 475 & 3.1 & & 6.5 & 32 & & 67 \\
\hline & E. nitens & 3.5 & 995 & 13.3 & 235 & & 455 & 4.5 & & 7.7 & 34 & & 58 \\
\hline Carrajung & E. nitens & 3.2 & 903 & 10.4 & 306 & & & 4.1 & & & 39 & & \\
\hline \multirow{2}{*}{ Mangalore } & E. globulus & 2.7 & 984 & 7.3 & 331 & & 537 & 3.6 & & 5.5 & 49 & & 75 \\
\hline & E. grandis & 3.8 & 939 & 7.6 & 334 & & 537 & 2.4 & & 3.3 & 32 & & 43 \\
\hline Rennick & E. globulus & 5 & 962 & 15.7 & 342 & 413 & 482 & 7.7 & 9.5 & 9.6 & 45 & 51 & 58 \\
\hline \multirow{2}{*}{ Shepparton } & E. globulus & 3.2 & 1071 & 11.4 & 361 & & 574 & 5.6 & & 7.7 & 49 & & 68 \\
\hline & E. grandis & 4.2 & 1065 & 9.6 & 361 & & 583 & 4 & & 6 & 42 & & 63 \\
\hline \multirow{2}{*}{ Tostaree } & E. globulus & 7.5 & 999 & 18.3 & 246 & & 444 & 6.3 & & 10.6 & 34 & & 58 \\
\hline & E. nitens & 7.5 & 1010 & 16.5 & 246 & & 442 & 7.1 & & 10.4 & 43 & & 63 \\
\hline
\end{tabular}


Table 3. Parameter estimates of Eqn. 1: basal area PAI $\left(\mathrm{cm}^{2}\right)=$ Constant + Slope $\ln \left(\right.$ competition; $\left.\mathrm{cm}^{2}\right)$ for trees belonging to the largest-diameter 200 trees $\mathrm{ha}^{-1}\left(D_{200}\right)$ size class. se is standard error.

\begin{tabular}{|c|c|c|c|c|c|c|c|}
\hline Site & Species & $\begin{array}{c}\text { Growth period } \\
\text { (age, years) }\end{array}$ & Constant (se) & Slope (se) & Adj. $R^{2}$ & $\mathrm{n}$ & $P$ \\
\hline Buffalo River & E. globulus & 3.5 to 5.5 & $116(12)$ & $-13.6(1.9)$ & 0.42 & 72 & $<0.001$ \\
\hline Buffalo River & E. globulus & 5.5 to 7.3 & $216(28)$ & $-23.3(4.3)$ & 0.30 & 67 & $<0.001$ \\
\hline Buffalo River & E. globulus & 7.3 to 9.6 & $178(26)$ & $-18.5(3.6)$ & 0.27 & 68 & $<0.001$ \\
\hline Buffalo River & E. nitens & 3.5 to 5.5 & $273(25)$ & $-33.6(3.8)$ & 0.58 & 57 & $<0.001$ \\
\hline Buffalo River & E. nitens & 5.5 to 7.3 & $397(76)$ & $-46.4(11.1)$ & 0.26 & 47 & $<0.001$ \\
\hline Buffalo River & E. nitens & 7.3 to 9.6 & $362(63)$ & $-41.9(8.6)$ & 0.31 & 52 & $<0.001$ \\
\hline Bradvale & E. globulus & 8.0 to 10.0 & $64(5)$ & $-7.4(0.8)$ & 0.35 & 169 & $<0.001$ \\
\hline Bradvale & E. globulus & 10.0 to 12.8 & 149 (11) & $-17.4(1.6)$ & 0.41 & 178 & $<0.001$ \\
\hline Mangalore & E. globulus & 6.3 to 10.1 & $156(38)$ & $-16.5(5.1)$ & 0.07 & 125 & 0.001 \\
\hline Mangalore & E. grandis & 6.3 to 10.1 & $84(16)$ & $-8.5(2.2)$ & 0.11 & 110 & $<0.001$ \\
\hline Rennick & E. globulus & 4.1 to 7.6 & $289(26)$ & $-32.2(3.7)$ & 0.38 & 123 & $<0.001$ \\
\hline Rennick & E. globulus & 7.6 to 9.6 & $430(36)$ & $-48.6(4.7)$ & 0.41 & 153 & $<0.001$ \\
\hline Rennick & E. globulus & 9.6 to 12.7 & $237(28)$ & $-24.6(3.6)$ & 0.24 & 149 & $<0.001$ \\
\hline Tostaree & E. globulus & 7.5 to 9.2 & $84(11)$ & $-7.3(1.7)$ & 0.04 & 425 & $<0.001$ \\
\hline Tostaree & E. globulus & 9.2 to 10.4 & $45(16)$ & $-1.3(2.4)$ & - & 403 & 0.577 \\
\hline Tostaree & E. globulus & 10.4 to 15.8 & $38(12)$ & $-0.4(1.7)$ & - & 404 & 0.813 \\
\hline Tostaree & E. nitens & 9.2 to 10.4 & $72(14)$ & $-4.1(2.1)$ & - & 427 & 0.056 \\
\hline Tostaree & E. nitens & 10.4 to 15.8 & $42(12)$ & $-0.4(1.8)$ & - & 412 & 0.815 \\
\hline Shepparton & E. globulus & 5.2 to 7.5 & $244(45)$ & $-23.7(5.9)$ & 0.11 & 117 & $<0.001$ \\
\hline Shepparton & E. globulus & 7.5 to 9.1 & $178(55)$ & $-17.3(7.0)$ & 0.04 & 115 & 0.015 \\
\hline Shepparton & E. grandis & 5.2 to 7.5 & $104(30)$ & $-8.8(4.2)$ & 0.04 & 83 & 0.041 \\
\hline Shepparton & E. grandis & 7.5 to 9.1 & $113(30)$ & $-12.1(4.0)$ & 0.09 & 83 & 0.004 \\
\hline Carrajung (unfert) & E. nitens & 3.2 to 4.4 & $252(26)$ & $-24.0(3.9)$ & 0.27 & 99 & $<0.001$ \\
\hline Carrajung (unfert) & E. nitens & 4.4 to 6.3 & $357(28)$ & $-36.9(4.0)$ & 0.40 & 126 & $<0.001$ \\
\hline Carrajung (unfert) & E. nitens & 6.3 to 8.1 & $392(30)$ & $-40.0(4.0)$ & 0.43 & 135 & $<0.001$ \\
\hline Carrajung (fert) & E. nitens & 3.2 to 4.4 & $273(25)$ & $-25.9(3.7)$ & 0.30 & 111 & $<0.001$ \\
\hline Carrajung (fert) & E. nitens & 4.4 to 6.3 & $318(27)$ & $-30.6(3.8)$ & 0.33 & 128 & $<0.001$ \\
\hline Carrajung (fert) & E. nitens & 6.3 to 8.1 & $400(35)$ & $-40.9(4.7)$ & 0.35 & 142 & $<0.001$ \\
\hline
\end{tabular}


Table 4. Equations describing the Slope of Eqn. 1 in Table 3 as a function of one or two of the explanatory variables (all ln-transformed) shown in the second line of the table. Site quality is quantified using $\mathrm{MAI}_{10}$ and size-class structure is quantified using statistics and parameters that describe the diameter distribution such as the coefficient of variation (CV), skewness, and Weibull $\beta$ or $\alpha$ parameters. $\mathrm{N}=27$ and $P<0.001$ for all equations. Standard errors are in parentheses.

\begin{tabular}{|c|c|c|c|c|c|c|}
\hline \multirow[b]{2}{*}{ Intercept } & \multicolumn{5}{|c|}{ Coefficients for explanatory variables } & \multirow[b]{2}{*}{ Adj. $R^{2}$} \\
\hline & $\mathrm{MAI}_{10}$ & $\mathrm{CV}$ & Skewness & Weibull- $\beta$ & Weibull- $\alpha$ & \\
\hline $3.8(6)$ & $-1.16(0.26)$ & & & & & 0.42 \\
\hline$-65.5(11)$ & & $1.58(0.38)$ & & & & 0.38 \\
\hline$-10.4(3)$ & & & $26.8(6.3)$ & & & 0.39 \\
\hline $112.2(25)$ & & & & $-233(43.4)$ & & 0.51 \\
\hline $8.5(8)$ & & & & & $-7.0(1.9)$ & 0.33 \\
\hline$-27.5(21)$ & $-0.75(0.36)$ & $0.81(0.51)$ & & & & 0.45 \\
\hline $2.5(6)$ & $-0.78(0.28)$ & & $16.4(6.8)$ & & & 0.51 \\
\hline $85.5(27)$ & $-0.61(0.28)$ & & & $-164(52)$ & & 0.57 \\
\hline $8.2(8)$ & $-0.88(0.4)$ & & & & $-2.4(2.7)$ & 0.41 \\
\hline$-42.1(14)$ & & $1.00(0.42)$ & $17.2(7.1)$ & & & 0.48 \\
\hline $53.5(29)$ & & $1.00(0.32)$ & & $-179(42)$ & & 0.63 \\
\hline $82.7(30)$ & & & $12.1(7.2)$ & $-173(55)$ & & 0.54 \\
\hline $102(23)$ & & & & $-185(44)$ & $-4.1(1.6)$ & 0.59 \\
\hline
\end{tabular}


Figure 1. Examples of the influence of size class on the relationship between basal area PAI and competition. Competition was expressed as the sum of the basal area of neighbouring trees within a radius of $6.5 \mathrm{~m}$ (Eqn. 1). For these multiple regressions (size class is included as a dummy variable) the Adj. $\mathrm{R}^{2}=0.52,0.52,0.28,0.30$, 0.27 and 0.23 for (a) to (f), respectively. Size classes are indicated as the 200 largest-diameter trees ha-1 $\left(D_{200}\right)$, the next largest $200\left(D_{200-400}\right)$, and then the next largest $\left(D_{400-600}\right)$.
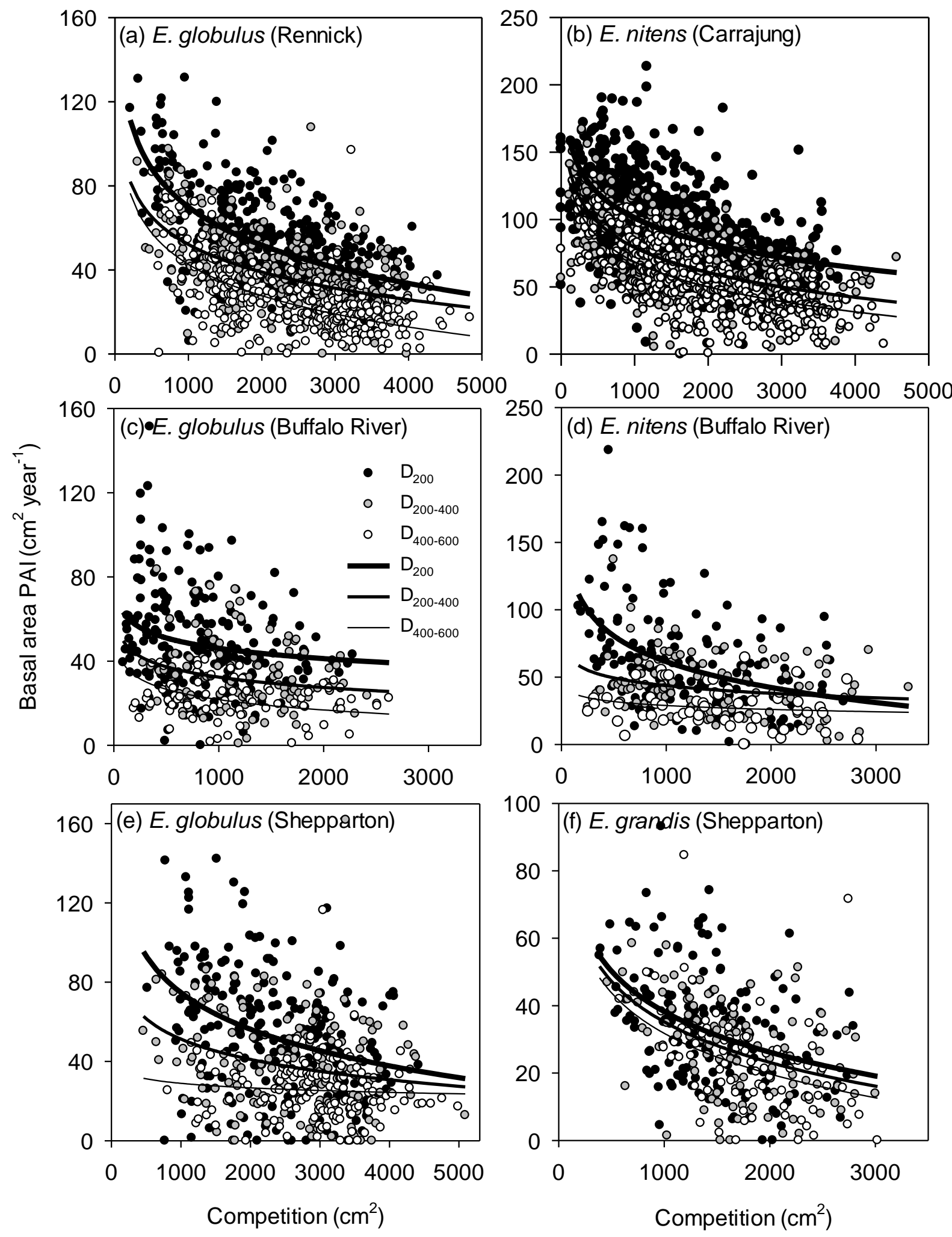
Figure 2. Example modelled relationships between basal area PAI of $D_{200}$ and competition, with constants and slopes representing the range of observed relationships (Eqn. 1, Table 3). The indicated absolute $\left(\mathrm{cm}^{2}\right.$ year-1) and relative (\%) competition responses are the difference in increment from a competition of $3000 \mathrm{~cm}^{2}$ to 800 $\mathrm{cm}^{2}$. The higher lines are representative of higher quality sites, where diameter distributions of unthinned stands are more negatively skewed, have lower coefficients of variation and higher Weibull- $\beta$ values (see Figure 3).

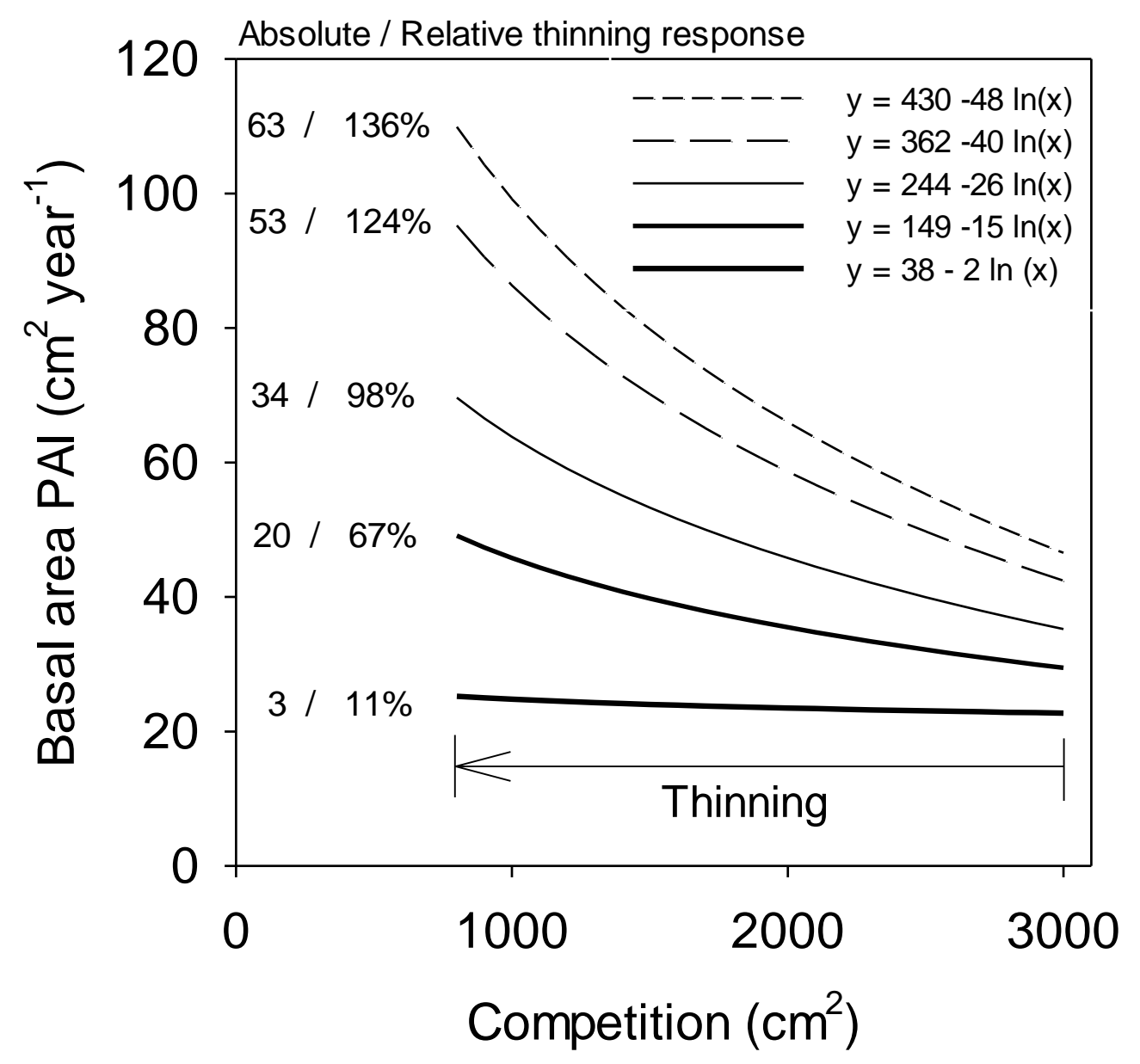

Figure 3. Relationships between the Slope (of the relationships between $D_{200}$ basal area PAI and Competition, Equation 1, Table 3) and site quality ( $\mathrm{MAI}_{10}$; a), the coefficient of variation (b), skewness (c) and the Weibull- $\beta$ (d) or Weibull- $\alpha$ (e). All relationships are significant $(P<0.001$; see Table 4$)$. 

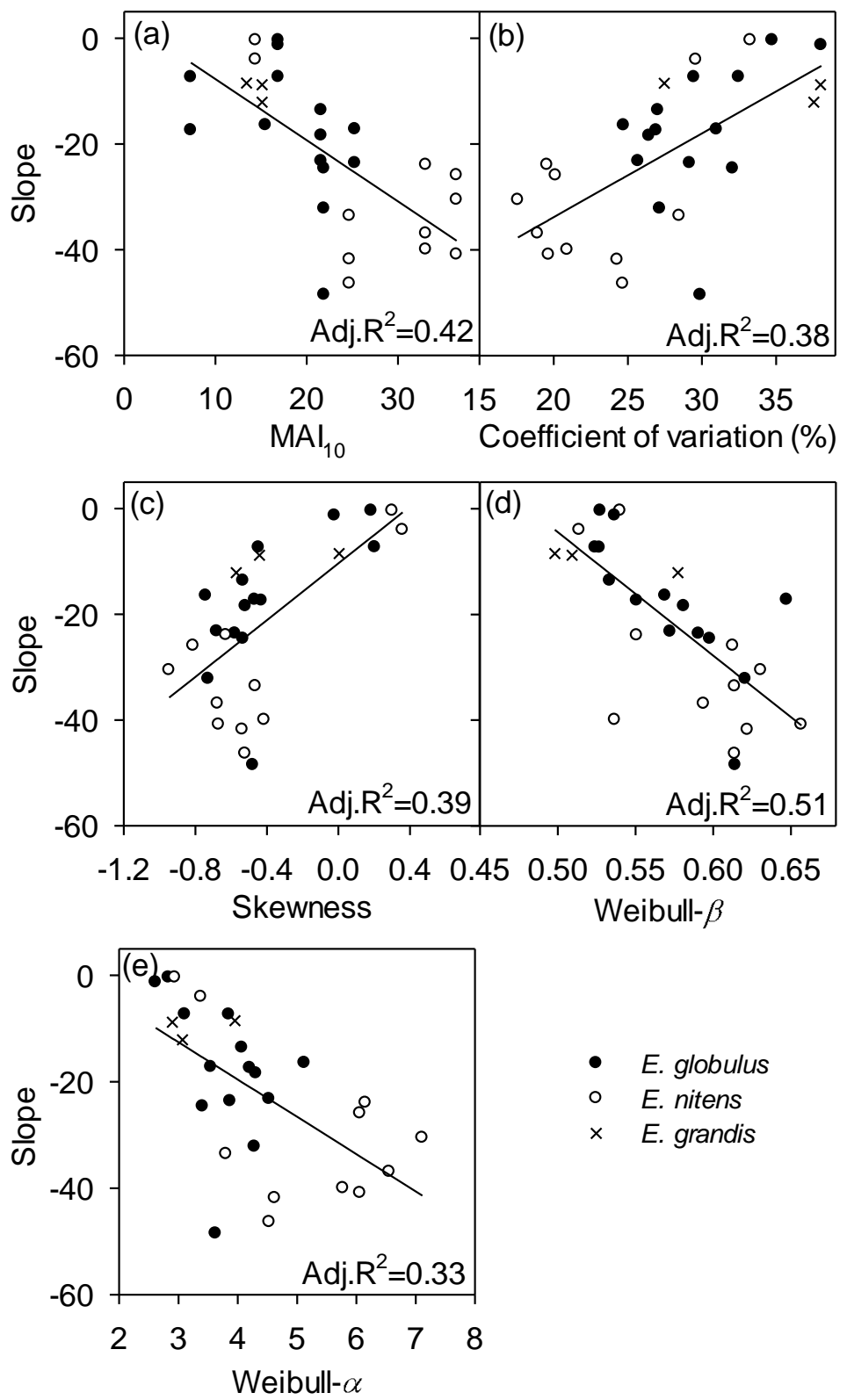

- E. globulus

- E. nitens

$\times \quad$ E. grandis 
Figure 4. Plots of site quality $\left(\mathrm{MAI}_{10}\right)$ and size-class structural parameters such as the coefficient of variation (a), skewness (b) and Weibull- $\beta$ parameter (c) of unthinned stands, indicating the poor correlation between site quality and size-class structure for E. globulus.

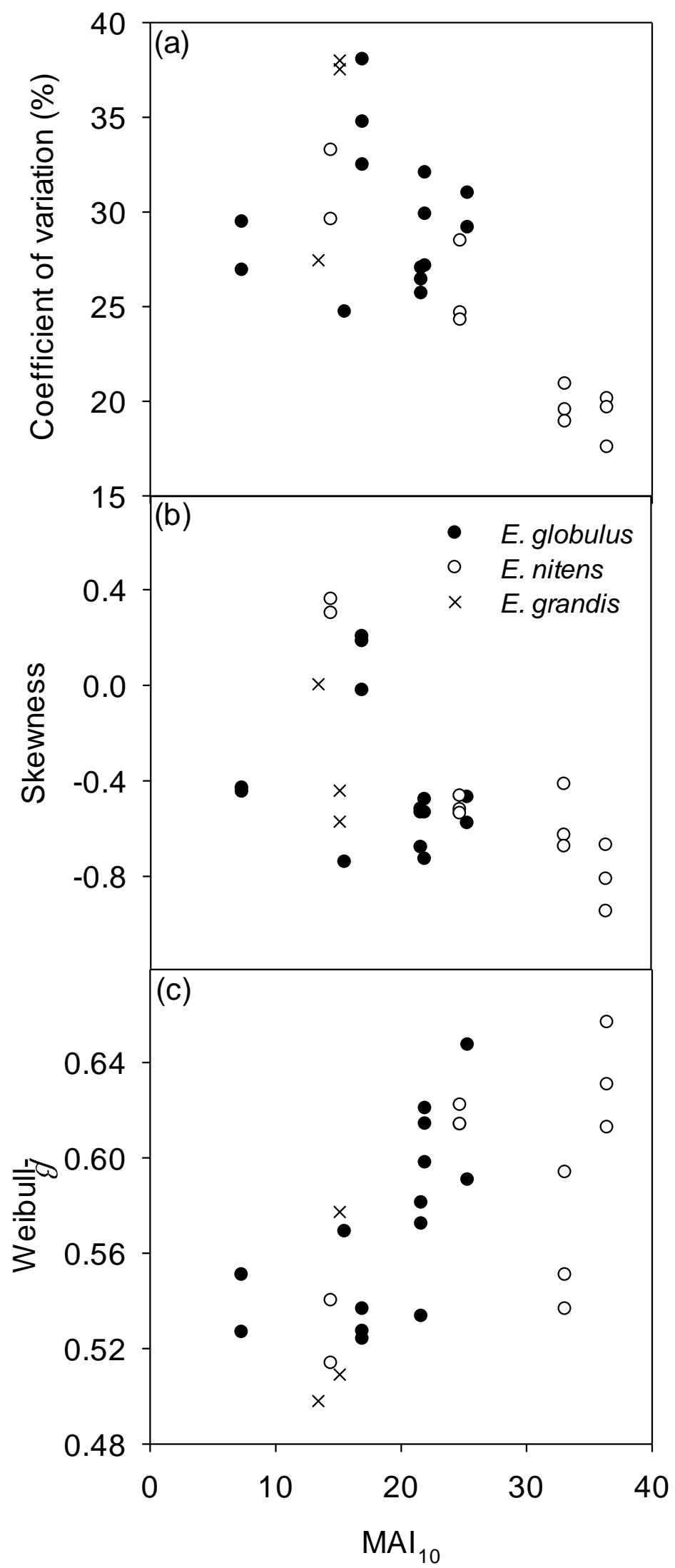


Figure 5. Diameter distributions for the unthinned treatments in stands exemplifying large (a), medium (b) and small (c) responses to reductions in competition from $3000 \mathrm{~cm}^{2}$ to 800 $\mathrm{cm}^{2}$.

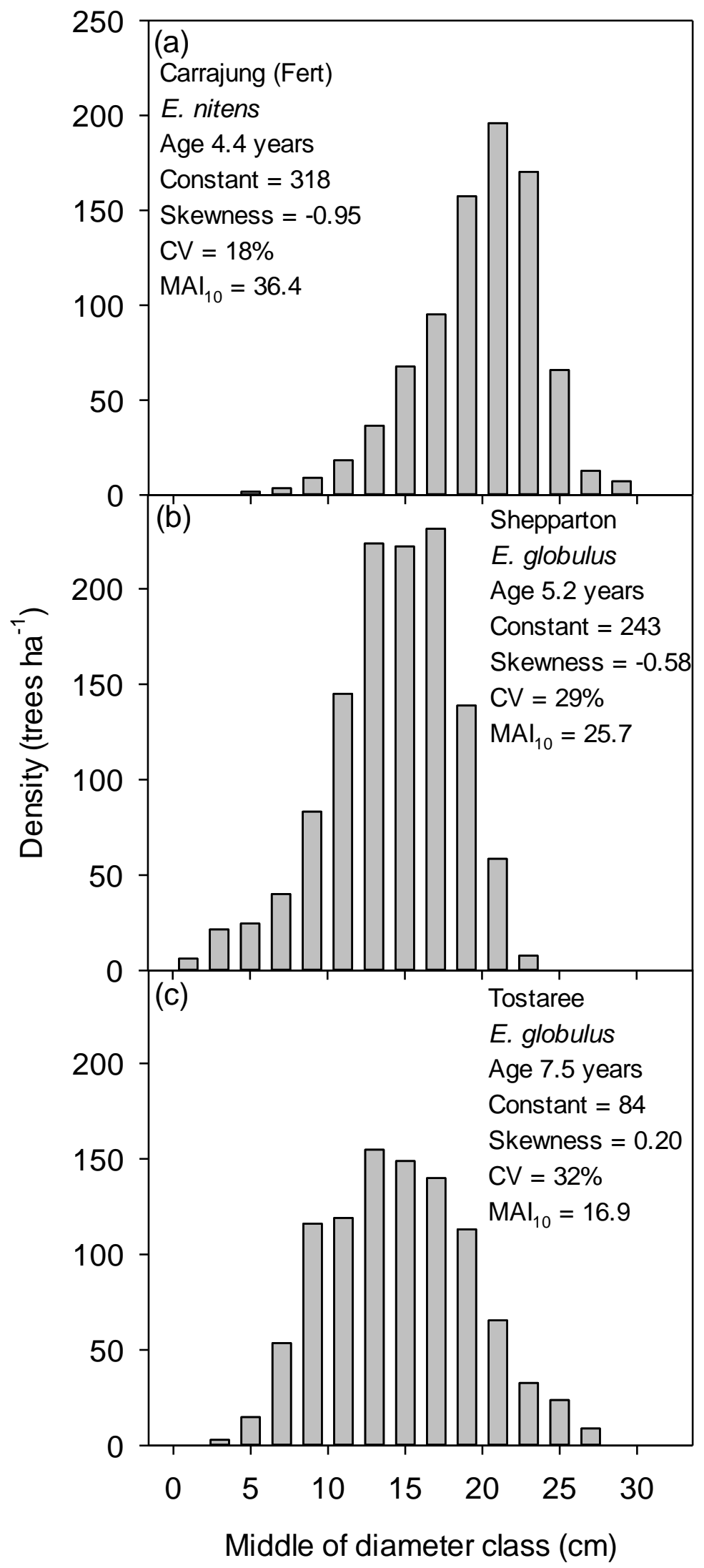




\section{University Library}

\section{- M M I N E R VA A gateway to Melbourne's research publications}

Minerva Access is the Institutional Repository of The University of Melbourne

Author/s:

Forrester, DI;Elms, SR;Baker, TG

Title:

Tree growth-competition relationships in thinned Eucalyptus plantations vary with stand structure and site quality

Date:

2013-03-01

Citation:

Forrester, D. I., Elms, S. R. \& Baker, T. G. (2013). Tree growth-competition relationships in thinned Eucalyptus plantations vary with stand structure and site quality. EUROPEAN JOURNAL OF FOREST RESEARCH, 132 (2), pp.241-252. https://doi.org/10.1007/ s10342-012-0671-0.

Persistent Link:

http://hdl.handle.net/11343/282571 